\title{
Neurobehavioral and neurochemical effects in rats offspring co-exposed to arsenic and fluoride during development
}

\author{
Sergio Dominguez，Ileana Lencinas， Mariana Bartos，Cristina Gallegos，Cristina Bras， Nina Mónaco, \\ Alejandra Minetti, Fernanda Gumilar*
}

Laboratorio de Toxicología, Instituto de Investigaciones Biológicas y Biomédicas del Sur (INBIOSUR), Departamento de Biología, Bioquímica y Farmacia, Universidad Nacional del Sur, Consejo Nacional de Investigaciones Científicas y Técnicas (CONICET), Depto. de Biología, Bioquímica y Farmacia, San Juan 670, 8000, Bahía Blanca, Argentina

\section{A R T I C LE IN F O}

Edited by Dr. P Lein and Dr. R Westerink

\section{Keywords}

Arsenic/Fluoride

Development exposure

Motor activity

Transaminases

Catalase

Acetylcholinesterase

Striatum

\begin{abstract}
A B S T R A C T
Arsenic (iAs) and fluoride (F) are ubiquitous in the environment. All over the world, in many countries, thousands of people are suffering from the toxic effects of arsenicals ad fluorides. These two elements are recognized worldwide as the most serious inorganic contaminants in drinking water. When two different types of toxicants are simultaneously going inside the human body they may function independently or can act as synergistic or antagonistic to one another. Although there have been reports in literature of individual toxicity of iAs and F, however, not much is known about the effects following the combined exposure to the toxicants above mentioned. In this work, we investigated the effect of the co-exposure to low levels of iAs/F through drinking water during pregnancy and lactation on central nervous system functionality in the exposed rats offspring. Wistar rats were exposed to one of these solutions: $0.05 \mathrm{mg} / \mathrm{L}$ iAs and $5 \mathrm{mg} / \mathrm{L} \mathrm{F}$ (Concentration A) or $0.10 \mathrm{mg} / \mathrm{L} \mathrm{iAs} \mathrm{and} 10 \mathrm{mg} /$ L F (Concentration B) from gestational day 0 up to post-gestational day 21. Sensory-motor reflexes a Functional Observational Battery and the locomotor activity in an open field were assessed in offspring. Additionally, the transaminases, acethylcholinesterase and catalase levels in the striatum were determined to elucidate the possible molecular mechanisms involved in locomotor and neurobehavioral disorders. The results showed that iAs/F exposition during development produces a delay reach the maturity of sensorimotor reflexes. A decrease in the nociceptive reflex response, and increase in the locomotor activity in adult rats offspring were observed. The increase in oxidative stress, the inhibition of transaminases enzymes and the inhibition of AChE in the striatum may partially regulate all the neurobehavioral disorders observed.
\end{abstract}

\section{Introduction}

Inorganic arsenic (iAs) and fluoride (F) are ubiquitous in the natural environment. Several geographic aquifers in many areas are naturally enriched with iAs and $\mathrm{F}$ because of similar geology. Arseniasis and fluorosis owing to drinkable water with high concentrations of arsenic and fluoride (iAs/F) prevails in some areas worldwide. In many countries, including Argentina, Bolivia, Chile, Colombia, Mexico, China, India, Japan and Korea an excess of iAs and $\mathrm{F}$ in the environment has been reported (Gonzalez-Horta et al., 2015). It is interesting to see that when these two elements enter the body simultaneously, they can interact independently of each other, or in a synergistic or antagonistic way, depending on the concentration of both elements in the water (Flora et al., 2012). Arsenic and fluoride are able to cross the blood-brain and placental barriers and both elements can be accumulated in the brain (Bartos et al., 2015; Gumilar et al., 2015; Luo et al., 2009; $\mathrm{Xi}$ et al., 2010). Low levels of $\mathrm{iAs}$ and $\mathrm{F}$ have been detected in the breast milk of women. These low levels have also been associated with adverse health effects on infants (Fangstrom et al., 2008; Sener et al., 2007). The above mentioned findings suggest that iAs and $F$ may cause impairment on fetal and infant health. Epidemiological and animal studies have shown that chronic arsenic or fluoride exposure may damage intellectual function in children and cognitive functions in rats offspring (Khan et al., 2015; Rodriguez et al., 2002; Wasserman et al., 2004). The individual neurotoxicity of iAs and $F$ is well reported. The neurotoxicity of arsenic exposure is well evidenced as it is consumed via drinking water. It is important to consider that Fluoride is toxic if it is consumed in excess but it is also considered of benefit to human health when it is consumed within the permissible limit (0.7-1.5 mg/L). Low concentrations of both agents during development, in concentrations slightly higher than those recommended by the WHO, produce neurotoxicity (Gumilar et al., 2015, 2018; Bartos et al., 2015, 2018, 2019). However, only few reports study the interaction between these two common water contaminants. Data on health

\footnotetext{
* Corresponding author at: Laboratorio de Toxicología, INBIOSUR-CONICET, Universidad Nacional del Sur, San Juan 670, 8000, Bahía Blanca, Argentina.

E-mail address: fgumilar@criba.edu.ar (F. Gumilar)
} 
effects are lacking or contradictory. Insufficient information about connections between fluoride-arsenic co-exposure and neurobehavioral disorders has been reported in the literature. Therefore, further research to reveal the neurotoxic effects of fluoride-arsenic co-exposure is needed.

The central nervous system (CNS) is much more susceptible to toxic agents in the early stages of growth and development. The embryonic period in humans and rodents is extremely sensitive to chemical toxicity (Anderson et al., 2000). Increased exposures to trace elements may result in undesirable consequences to human health, and as such, the developing brains have seen to be a highly vulnerable target organ (Grandjean et al., 2014). Several researchers suggest that arsenic and fluorine perinatal exposure cause locomotion disorders. The striatum is one of the areas that regulates the locomotor activity. The dorsal striatum receives nigrostriatal dopaminergic projections from the substantia nigra pars compacta (SNpc), as well as glutamatergic projections from several brain areas, including the somatosensory cortices, amygdala, and hippocampus (Britt et al., 2012). This process indicates an integration of dopaminergic and glutamatergic neurotransmissions in the dorsal striatum. Moreover, it is important to consider that the striatum is one of the areas in the brain with the highest concentration of acetylcholine (ACh) and its associated enzymes choline acetyltransferase (ChAT) and acetylcholinesterase (AChE). Acetylcholine coordinates the neuronal networks of the brain cholinergic modulation area (Vathana et al., 2014).

The underlying molecular mechanisms of iAs or F toxicity are not fully understood, but generation of reactive oxygen species (ROS) and reactive nitrogen species (RNS) during metabolism is postulated as a possible mechanism (Basha and Madhusudhan, 2010; Liu et al., 2011; Rodriguez et al., 2010). Several previous studies revealed that individual iAs or $\mathrm{F}$ exposure induces to excessive free radical oxygen production and it may cause a biological activity decrease in some antioxidants enzymes such as catalase (CAT) and glutathione peroxidase (GPx). If antioxidant defenses are surpassed, iAs or F may also cause alterations at the transcriptional level in neurotransmission systems (Bardullas et al., 2009; Xi et al., 2010).

We have recently shown that a low level exposure to iAs $(0.05$ and $0.1 \mathrm{mg} / \mathrm{L}$ ) and to $\mathrm{F}$ (5 and $10 \mathrm{mg} / \mathrm{L}$ ) during pregnancy and lactation affects neither maternal weight gain during pregnancy nor gestational length, litter size and pup body weight on different postnatal days (PNDs). However, persistent sensory-motor changes were observed in rats offspring exposed to iAs through maternal drinking water during gestation and lactation. A delay in the development of the righting reflex, cliff aversion and negative geotaxis was observed in offspring whose dams had been exposed to 0.05 or $0.10 \mathrm{mg} / \mathrm{L}$ iAs concentrations. We have also observed that offspring exposed to iAs during development, showed less nociceptive response and hypoactivity compared to the offspring control (Gumilar et al., 2015). Moreover, the exposure to $0.10 \mathrm{mg} / \mathrm{L}$ iAs during this critical period produced a significant impairment in the long-term memory (LTM) retention in adult female offspring. This cognitive alteration might be related to several events that occur in the hippocampus: decrease in $\alpha 7$-nAChR expression, an increase of glutamate levels that may produce excitotoxicity, and a decrease in the antioxidant enzyme catalase (CAT) activity (Monaco et al., 2018).

It is hypothesized that $\mathrm{F}$ exposure during gestation and lactation may cause structural alterations in the neuronal circuit which later presented as functional deficits. We show that early exposition to 5 and $10 \mathrm{mg} /$ $\mathrm{L} \mathrm{F}$ in drinking water during gestational and lactation produces a delay in the eyes opening of the offspring. Exposure to low F concentrations was also found to significantly decrease locomotor activity only in 90-day-old male and female offspring. A low index of anxiety in the young females and in all adult offsprings exposed to the two F concentrations tested was also detected (Bartos et al., 2015). Moreover, low
F concentrations administrated during gestation and lactation impairs the memory of adult female offspring. This suggests that the mechanism might be connected with an $\alpha 7$ nAChR deficit in the hippocampus, induced by oxidative stress (Bartos et al., 2018).

Although developmental neurotoxicity of iAs or F in rats offspring by transplacental and early life exposure in drinking water has been studied (Bartos et al., 2015; Gumilar et al., 2015; Monaco et al., 2018; Xi et al., 2009), there is little information about the teratogenic effects of exposure to low levels of co-exposure to iAs/F during gestation and lactation. Taking into account all the above mentioned, our hypothesis is that the co-exposure to low concentrations of iAs/F during pre and postnatal development may cause an imbalance of neurotransmitters levels in the striatum, causing neurobehavioral alterations in adulthood. The purpose of the present work was to study the effect of the co-exposure to low levels of iAs/F during pregnancy and lactation on CNS functionality. Wistar rats were exposed to concentration A: $0.05 \mathrm{mg} / \mathrm{L}$ iAs and $5 \mathrm{mg} /$ $\mathrm{L} \mathrm{F}$ or concentration B: $0.10 \mathrm{mg} / \mathrm{L}$ iAs and $10 \mathrm{mg} / \mathrm{L} \mathrm{F}$ during pregnancy and lactation and nervous system functionality was analyzed. Neurobehavioral studies and neurochemical determinations in the striatum were carried out to elucidate the possible mechanisms involved in the neurobehavioral disorders observed.

\section{Materials and methods}

\subsection{Materials}

Sodium arsenite $\left(\mathrm{AsNaO}_{2}\right)$ was purchased from Sigma-Aldrich (St. Louis, MO, USA) and protected from sunlight. Sodium fluoride (NaF) was purchased from Anedra (San Fernando, Argentina).

\subsection{Animals and experimental design}

Parent animals were male and nulliparous female Wistar rats (90-120 days old) obtained from the animal colony at the Bioterio of the Departamento de Biología, Bioquímica y Farmacia, Universidad Nacional del Sur, Bahía Blanca, Argentina. The rats were maintained under the following conditions: temperature $\left(22^{\circ} \pm 1{ }^{\circ} \mathrm{C}\right)$ and humidity $(50 \%-60$ $\%)$ in a $12 \mathrm{~L}: 12 \mathrm{D}$ cycle (lights on at 7:00 h) and with food and water ad libitum. The evening of the females' proestrus day, male and female rats were housed overnight in couples. The presence of spermatozoa in the vaginal smears was registered as an index of pregnancy and was referred to as gestational day (GD) 0. Pregnant females were weighed and housed individually and were randomly assigned to one of the three following groups: Control group, concentration A: group treated with $0.05 \mathrm{mg} / \mathrm{L}$ iAs and $5 \mathrm{mg} / \mathrm{L} \mathrm{F}$ in drinking water, and concentration B: group treated with $0.10 \mathrm{mg} / \mathrm{L}$ iAs and $10 \mathrm{mg} / \mathrm{L} \mathrm{F}$ in drinking water. Arsenic and fluoride concentrations chosen in this work are approximately 5 and 10 times higher than those allowed by the WHO in drinking water. These concentrations are present in groundwater in different parts of the world. Sodium arsenite and sodium fluoride were dissolved in tap water and were administered to pregnant rats from GD 0 to postgestational day (PGD) 21. Control group received tap water. Bahía Blanca tap water contains traces of iAs and $\mathrm{F}$ that do not interfere with the experimental design $\left(<1 \times 10^{-4} \mathrm{mg} / \mathrm{L}\right.$ iAs and $<0.5 \mathrm{mg} / \mathrm{L} \mathrm{F}$, respectively). Maternal weight gain, water consumption and food intake were recorded at different GDs as describe Gumilar et al., 2015.

The number of pregnant dams that delivered live litters was $\mathrm{n}=8-10$ in the control group and exposed ones. Within $24 \mathrm{~h}$ after birth litter size was determined and all pups were weighed. On postnatal day (PND) 3, litter size was randomly maintained at five males and five females whenever possible. The following date were registered: gestation length, litter size and body weight of pups on different PNDs as describe Gumilar et al., 2015. On PND 21, pups were weaned and housed in groups of six rats according to sex and treatment until PND 
90. One male and female from each litter were used for the same behavioral test. In all experiments, the observer was blind to the treatment conditions.

\subsection{Sensory-motor development}

Starting on PND 3, each pup was subjected to a battery of sensory-motor developmental test. One trial test per day was given to the pups on each test: righting reflex, cliff aversion, negative geotaxis and eye and ear opening. The dependent variable analyzed for each test consisted of the number of PND until each pup reached maturity of the reflex or condition according to the criteria listed below (Molina et al., 1987).

\subsubsection{Righting reflex}

Each pup was placed on its back on a cloth-covered supporting surface and allowed to right itself. This reflex was registered as mature if the pup performed this response within $5 \mathrm{~s}$ on 2 consecutive days.

\subsubsection{Cliff aversion}

Each pup was placed with their forepaws on the edge of a wooden platform and the snout protruded beyond the edge of the same platform. Latency to retract their body $1.5 \mathrm{~cm}$ from the edge was registered. Cliff aversion criterion was registered as mature when the pup performed this response in less than $5 \mathrm{~s}$ on 2 consecutive days.

\subsubsection{Negative geotaxis}

Each pup was placed on an inclined wire mesh ramp (angle of inclination from the base: $30^{\circ}$ ) with the head facing down. This reflex was registered as mature when the pup reached a $180^{\circ}$ rotation of the body and climbing upwards was done within $10 \mathrm{~s}$ on 2 consecutive days.

\subsubsection{Eye and ear opening}

The PND on which both eyes and auditory canals were fully opened was registered.

\subsection{Functional observational battery}

The 90-day-old offspring were used for this test. Functional observational battery (FOB) included a thorough description of the animals' appearance, behavior and functional integrity (US EPA, 1998). This was assessed through observations in the cage, in an open field and through manipulative tests. Procedural details and scoring criteria for FOB protocol have been published (McDaniel and Moser, 1993). Briefly, measurements were first carried out in the home cage. The observer recorded each animal's posture, activity and palpebral closure. The presence or absence of tremors and convulsions was noted and, if present, described. The presence or absence of spontaneous vocalizations and biting was also noted. The observer then removed the animal, rating the ease of removal and handling. The presence or absence of hindlimb flexor resistance and pressure grade was also recorded. Palpebral closure and any sign of lacrimation or salivation were rated. Other abnormal clinical signs were also recorded. The animal was next placed in FOB experimental arena having a piece of clean absorbent paper on the surface. In the experimental arena, the rat gait score and any abnormal posture, unusual movements and stereotypies were ranked. Also, the number of fecal boluses and urine pools and the presence or absence of diarrhea on the absorbent paper were recorded. Sensorial responses were subsequently ranked according to a variety of stimuli as describe in detail in Gumilar et al., 2015. Also, several motor reflexes were analyzed (flexor and extensor thrust reflexes, forelimb hopping, propioceptive positioning). Forelimb and hindlimb extensions were registered in the gait analysis. Degree of surface and aerial righting was subsequently rated. In landing foot splay, the tarsal joint pad of each hindfoot was marked with ink and the animal was subsequently dropped from a height of $30 \mathrm{~cm}$ onto a recording sheet. This procedure was repeated twice. The distance from center-to-center of the ink marks was measured $(\mathrm{cm})$ and the average of the two splay values was used for statistical analysis.

\subsection{Open field observations}

The open field test is an experimental test used to assay general locomotor activity levels and is considered to be a test of nervous system function. It reflects the integrated output of the sensory, motor and associative processes of the nervous system in absence of systemic toxicity (Hubler et al., 2005). Locomotor activity was analyzed in an open field. Each 90-day-old offspring was placed in an open field of $50 \mathrm{~cm} \times 50 \mathrm{~cm} \times 60 \mathrm{~cm}$ whose floor was divided into $12 \mathrm{~cm} \times 12 \mathrm{~cm}$ squares by black lines. The number of squares entered by each rat with all four paws, rearings (occasions on which the animals stood on their hind paws), groomings (face washing, forepaw licking and head stroking) and fecal boluses were scored each $5 \mathrm{~min}$ for $15 \mathrm{~min}$. The number of squares crossed and the rearings performed were recorded as parameters of locomotor activity, whereas the number of groomings and the number of fecal boluses deposited were considered as parameters of emotionality (Maimanee et al., 2003). After each animal was removed, the open field was carefully cleaned with a cloth embedded with $10 \%$ ethanol solution. The test was carried out in the same time slot to avoid differences in the locomotor activity of the offspring.

\subsection{Preparation of brain homogenates}

Ninety-day-old offspring were sacrificed by decapitation. The striatum was collected using the atlas of Paxinos and Watson as a guide for tissue dissection (Paxinos and Watson, 2007). Striatum was homogenized with disposable homogenization pestles in 10 volumes $(1: 10, \mathrm{w} / \mathrm{v})$ of ice-cold phosphate buffer saline (PBS; pH 7.4). The homogenate was centrifuged at $4000 \mathrm{xg}$ and the resultant supernatants were kept at $4{ }^{\circ} \mathrm{C}$ until the neurochemical determinations. A supernatant aliquot of each sample was reserved for protein determination.

\subsection{Neurochemical determinations}

\subsubsection{Glutamate transaminases activity}

The activities of glutamate oxaloacetate transaminase (GOT), glutamate pyruvate transaminase (GPT) were evaluated in striatum homogenates of PND90 offspring, by spectrophotometric methods (Shimadzu UV-1203, UV-vis spectrophotometer) using the corresponding commercial kits of Wiener Lab. (Rosario, Argentina) following the manufacturers' indications.

\subsubsection{Catalase (CAT) assay}

Catalase activity of each brain samples were assayed following the procedure of Aebi (Aebi, 1984), with a slight modification. The catalase activity was measured by calculating the rate of degradation of hydrogen peroxide, the substrate of the enzyme. The enzyme activity was expressed as the rate constant of a first-order reaction (k) related to the protein content.

\subsubsection{Acetylcholinesterase (AChE) determination}

The activity of the enzyme AChE was determined following the Ellman's method (Ellman et al., 1961). Briefly, an aliquot of each supernatant was incubated with acetylthiocholine iodide (substrate) and 5,5'-dithio-bis(2-nitrobenzoic acid) (DTNB) for $10 \mathrm{~min}$ at $30{ }^{\circ} \mathrm{C}$. Enzymatic reaction was stopped by addition of eserine solution and incubation at $0{ }^{\circ} \mathrm{C}$ for $10 \mathrm{~min}$. The absorbance was measured at $420 \mathrm{~nm}$. AChE activity was calculated from a standard curve prepared with different 
concentrations of reduced glutathione, and expressed as micromole of thiocholine generated per minute per milligram of protein.

\subsubsection{Protein assay}

The protein concentration of the supernatants was measured using the method of (Bradford, 1976). Bovine serum albumin was used as a standard.

\subsection{Statistics}

Data from dams and their litters were analyzed by one-way ANOVA. Data of water consumption and food intake of dams as well as the weight of dams and pups were analyzed by repeated-measure ANOVA.

Each sensory-motor development test was analyzed by a two-way ANOVA followed by post hoc comparisons. FOB results were analyzed according to the type of data. Continuous data (providing interval data) were tested using a two-way ANOVA followed by post hoc comparisons. The ranked data (ranks based on a defined scale) were analyzed using Kruskal-Wallis nonparametric test followed by Mann-Whitney test. For descriptive and binary data (the presence or absence of a sign), each experimental group was compared to the control group using a chi-square test. Data obtained in 15 total minutes of observation in the Open Field were analyzed using a two-way ANOVA followed by post hoc comparisons. For the comparative analysis of the parameters analyzed every $5 \mathrm{~min}$, a repeated-measure ANOVA test was used. Neurochemical determinations were analyzed using a two-way ANOVA followed by post hoc comparisons.

Probability values lower than 0.05 were considered significant. All statistical analyses were carried out using IBM SPSS 21.0 (Chicago, IL) software for Windows.

\subsection{Ethics}

Animal care and handling were in accordance with the internationally accepted standard Guide for the Care and Use of Laboratory Animals (2011) as adopted and promulgated by the National Institute of Health. Experimental designs were also approved by the local standard for protecting animal's welfare, Institutional Committee for the Care and Use of Experimental Animals of the Universidad Nacional del Sur (Protocol Number 077/2018).

\section{Results}

\subsection{Data from dams and their litters}

Exposure to low levels of iAs/F combination during the prenatal period and during the lactation affects neither maternal weight gain during pregnancy nor the gestational length, the litter size and the pup body weight on different PNDs (Fig. 1A and Table 1) as the same manner that individual iAs or F exposure (Gumilar et al., 2015; Bartos et al., 2015). No visible teratogenic malformation was observed in any of the groups analyzed.

No statistically significant differences were observed in water and food intake during pregnancy and lactation in the dams exposed to both iAs/F concentrations, compared to the control group (Fig. 1B and C). As shown in Fig. 1C, the increase in drink consumption during lactation was probably due to the increased fluid requirements of the lactating dams and water consumption from pups, particularly during the last stage of the pre-weaning period. The same was observed with food intake (Fig. 1B).

\subsection{Sensory-motor reflexes}

When sensory-motor development tests were analyzed (Fig. 2), two-way ANOVA detected significant differences between groups in the righting reflex $\left(\mathrm{F}_{(2,54)}=4.91, \mathrm{p}<0.01\right)$. Post hoc comparisons showed that exposure to A and B concentration produced a significant delay in the development of the righting reflex in female rats $(\mathrm{p}<0.01$, in both concentrations) while no significant differences were observed in the male rats (Fig. 2A).

In the analysis of cliff aversion data differences between groups was detected by two-way ANOVA $\left(\mathrm{F}_{(2,54)}=10.02, \mathrm{p}<0.001\right)$. Post hoc comparisons showed that exposure to $\mathrm{B}$ concentration delayed the development of this reflex in female rats $(\mathrm{p}<0.02)$. On the other hand, the delay in the acquisition of cliff aversion was observed in males exposed to both concentrations ( $\mathrm{p}<0.01$ ) (Fig. 2B).

When negative geotaxis was analyzed, two-way ANOVA also detected significant differences between groups $\left(\mathrm{F}_{(2,54)}=9.91\right.$, $\mathrm{p}<0.001)$. Post hoc comparisons showed that female rats exposed to both concentrations had a delayed maturation of the reflex $(\mathrm{p}<0.01$ and $\mathrm{p}<0.02$ for $\mathrm{A}$ and $\mathrm{B}$ concentrations, respectively). Furthermore, the male offspring exposed to A concentration had a delay in acquiring this reflex ( $p<0.01$ ) (Fig. 2 C).

With respect to eye opening in offspring, two-way ANOVA revealed significant differences between groups $\left(\mathrm{F}_{(2,54)}=16.26, \mathrm{p}<0.001\right)$. Post hoc comparison showed that gestational and lactation exposure to both iAs/F concentrations produced a significant delay in this parameter in both sexes offspring $(\mathrm{p}<0.01$ for female and $\mathrm{p}<0.05$ for male offspring exposed to A concentration, $\mathrm{p}<0.05$ for female and male offspring exposed to B concentration, respectively) Table 1 . With respect to ear opening, two-way ANOVA revealed significant differences between groups $\left(\mathrm{F}_{(2,54)}=34.09, \mathrm{p}<0.001\right)$. Post hoc comparison showed that female and male offspring exposure to both iAs/F concentrations produced a significant delay in the ear opening ( $p<0.01$ for A and B concentrations, respectively) (Table 1).

\subsection{Functional observational battery}

Table 2 show the data obtained from the Functional Observational Battery (FOB) test. According to a variety of stimuli, sensorial responses were ranked. In tail pinch response, significant differences between groups were observed in female $\left(\chi_{(2)}^{2}=20.73, \mathrm{p}<0.001\right.$ and male $\left(\chi^{2}{ }_{(2)}=14.76, \mathrm{p}<0.001\right)$ offspring. We observed that the groups treated with both concentrations evidenced a lower response than that of the respective control group $(\mathrm{p}<0.01$ ). No statistically significant differences were observed in the other parameters analyzed in the FOB.

\subsection{Open field}

In open field observations (Fig. 3), the two-way ANOVA showed significant differences between group $\left(\mathrm{F}_{(2,54)}=9.956, \mathrm{p}<0.001\right)$ in the number of squares crossed by rats during $15 \mathrm{~min}$. Post hoc comparisons showed that rats of both sexes exposed to B concentration exhibited a significant increase in squares crossed compared to the control group $(\mathrm{p}<0.002)$ (Fig. 3A).

When the number of squares crossed in each 5 min period was compared, ANOVA for repeated measures showed significant differences within group $\left(\mathrm{F}_{(2,54)}=200,56 \mathrm{p}<0.001\right)$. The number of squares crossed in each period of 5 min was used to evaluate the habituation of rats to the open field. All groups showed higher locomotor activity during the first $5 \mathrm{~min}$ period and declined significantly in the second and in the third period ( $\mathrm{p}<0.01$ for all comparisons). This gradual and 

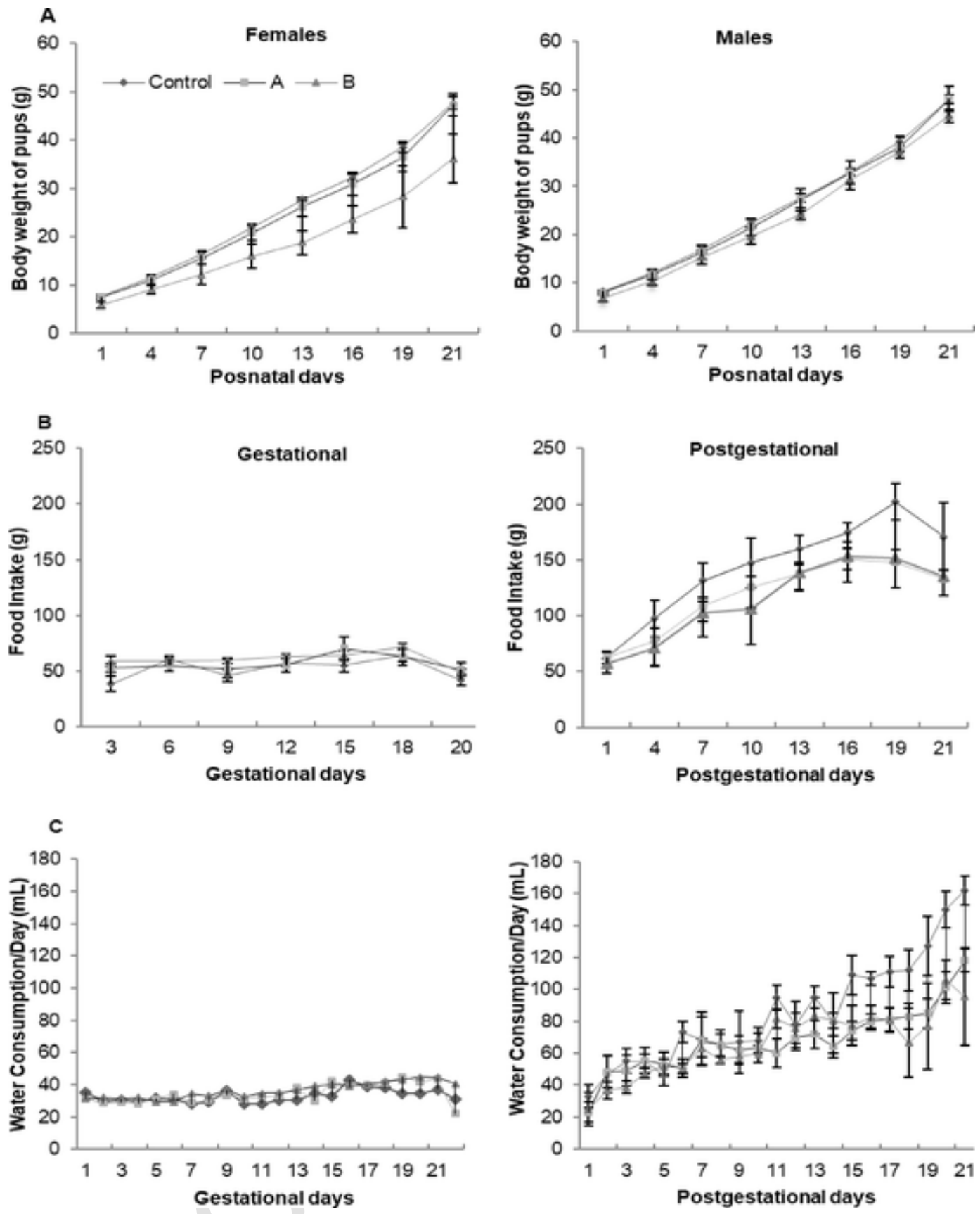

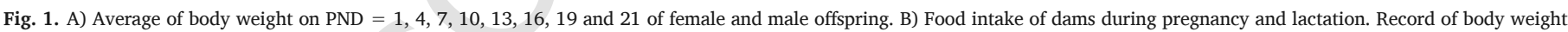

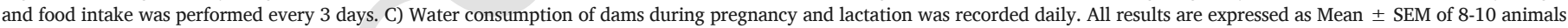
per group.

significant decrease in their locomotion activity throughout the test session indicated that all animals have habituated to the open field.

When the number of rearing was analyzed in the open field, two-way ANOVA showed significant differences between groups $\left(\mathrm{F}_{(2,51)}=21.55\right.$ $\mathrm{p}<0.001)$ and sexes $\left(\mathrm{F}_{(1,51)}=5.487 \mathrm{p}<0.02\right)$. Post hoc comparisons showed that offspring exposed to both concentrations exhibited a significant increase in number of rearings compared to the control group ( $\mathrm{p}<0.002$ for females and males offspring) (Fig. 3B).

The numbers of rearings in periods of $5 \mathrm{~min}$ was also analyzed to evaluate habituation. ANOVA for repeated measured showed significant differences within group $\left(\mathrm{F}_{(2,54)}=333,54 \mathrm{p}<0.001\right)$. All groups showed higher rearing activity during the first $5 \mathrm{~min}$ period, and declined in the second and in the third period ( $\mathrm{p}<0.01$ for all compar- isons) (Fig. 3B). However, we can observe in each 5-minute period, significant increases in the number of rearings in offspring exposed to both concentrations, compared to the control. Analysis of the number of groomings and fecal boluses, both considered as emotionality parameters, revealed no statistically significant differences between the control and experimental groups (data not shown).

\subsection{Neurochemical determinations in striatum}

\subsubsection{Glutamate transaminases activity}

To evaluate the glutamatergic pathway, we indirectly measured transaminases levels in 90-day-old rats. As shown in Fig. 4, transaminases concentrations in supernatant of striatum area of control and 
Table 1

Data from mothers and their litters.

\begin{tabular}{|c|c|c|c|}
\hline & Control group & A & B \\
\hline & $\mathrm{n}=8$ & $\mathrm{n}=10$ & $\mathrm{n}=9$ \\
\hline \multicolumn{4}{|l|}{ Body weight of dams (g) } \\
\hline GD 0 & $276.3 \pm 13.3$ & $300.8 \pm 28.7$ & $299.8 \pm 8.8$ \\
\hline \multicolumn{4}{|l|}{ Weight gain (g) } \\
\hline GD $0-3$ & $17.7 \pm 4.2$ & $9.25 \pm 4.1$ & $13.8 \pm 2.2$ \\
\hline GD 3-6 & $9.3 \pm 3.5$ & $8.5 \pm 1.7$ & $5.4 \pm 1.6$ \\
\hline GD 6-9 & $6.7 \pm 3.9$ & $7.2 \pm 1.2$ & $5.4 \pm 1.5$ \\
\hline GD 9-12 & $15.3 \pm 4.2$ & $17.5 \pm 2.7$ & $17.2 \pm 2.6$ \\
\hline GD $12-15$ & $14.7 \pm 1.9$ & $16.7 \pm 4.9$ & $13.4 \pm 2.1$ \\
\hline GD 15-18 & $32.7 \pm 8.1$ & $28.5 \pm 2.4$ & $25.2 \pm 2.0$ \\
\hline GD 18-20 & $25.3 \pm 6.9$ & $27.0 \pm 2.7$ & $25.4 \pm 3.1$ \\
\hline GD 0-20 & $122.3 \pm 192$ & $1148 \pm 8.0$ & $105.8 \pm 7.7$ \\
\hline Length of gestation (days) & $22.0 \pm 0$ & $22.0 \pm 0$ & $22.0 \pm 0$ \\
\hline \multicolumn{4}{|l|}{ Litter size } \\
\hline Female & $4.3 \pm 1.9$ & $5.8 \pm 1.0$ & $4.2 \pm 1.0$ \\
\hline Male & $6.3 \pm 0.7$ & $3.7 \pm 0.6$ & $3.6 \pm 0.9$ \\
\hline Total & $10.7 \pm 2.3$ & $9.5 \pm 1.2$ & $7.8 \pm 1.3$ \\
\hline \multicolumn{4}{|l|}{ Eye Opening (days) } \\
\hline Female & $13.2 \pm 0.2$ & $14.4 \pm 0.3^{* *}$ & $14.6 \pm 0.2^{* *}$ \\
\hline Male & $13.5 \pm 0.2$ & $14.3 \pm 0.4^{*}$ & $15.0 \pm 0.2^{* *}$ \\
\hline \multicolumn{4}{|l|}{ Ear Opening (days) } \\
\hline Female & $11.2 \pm 0.1$ & $13.2 \pm 0.3^{* *}$ & $12.9 \pm 0.3^{* *}$ \\
\hline Male & $11.2 \pm 0.1$ & $13.0 \pm 0.3^{* *}$ & $12.9 \pm 0.3^{* *}$ \\
\hline \multicolumn{4}{|l|}{ Weight PND 90 (g) } \\
\hline Female & $280.3 \pm 10.3$ & $2625 \pm 7.6$ & $272.5 \pm 7.6$ \\
\hline Male & $412.3 \pm 18.7$ & $408.2 \pm 8.5$ & $398.3 \pm 7.7$ \\
\hline
\end{tabular}

Values are mean \pm SEM. Gestational weights represent the pregnant rats that delivered the live litters that were assessed in this study. ${ }^{*} \mathrm{p}<0.05$ and ${ }^{* *} \mathrm{p}<0.01$ compared to the control group.

treated groups were assessed. Two-way ANOVA showed significant differences between groups $\left(\mathrm{F}_{(2,24)}=8,442, \mathrm{p}<0.001\right)$ and sexes $\left(\mathrm{F}_{(1,24)}=15,949, \mathrm{p}<0.001\right)$ in GPT levels in striatum area. Post hoc comparisons showed a significantly decrease in female offspring exposed to $\mathrm{A}$ and $\mathrm{B}$ concentrations compared to female control group ( $\mathrm{p}<0.005$ for A concentration and $\mathrm{p}<0.05$ for B concentration). No significant differences were observed in GPT levels in the striatum of treated males. With respect to GOT in striatum area, two-way ANOVA showed significant differences between groups $\left(\mathrm{F}_{(2,24)}=7.638, \mathrm{p}<0.002\right)$ and sexes $\left(\mathrm{F}_{(1,24)}=5.909, \mathrm{p}<0.02\right)$ and interaction $\left(\mathrm{F}_{(2,24)}=8.588\right.$, $\mathrm{p}<0.001)$. Post hoc comparisons showed a biphasic effect in female offspring treated group. A significant decrease was observed in female offspring exposed to A concentration $(\mathrm{p}<0.005)$ and a significant increase in female offspring exposed to B concentration ( $\mathrm{p}<0.05$ ), compared to the control group. In contrast, male offspring exposed to both iAs/F concentrations, showed a significant decrease in striatum GOT levels, compared to the control group ( $\mathrm{p}<0.05$ ).

\subsubsection{Catalase activity}

In order to identify whether the neurobehavioral effects observed are due to oxidative stress stimulated by co-exposure to iAs/F during the gestational and lactation, we studied the catalase anti-oxidative enzyme activity in the striatum of 90-day old rats offspring. Fig. 5 illustrates the catalase activity in the striatum of the control and experimental groups of adult offspring exposed to A and B concentrations during development.

Two-way ANOVA showed a significant difference between groups $\left(\mathrm{F}_{(2,24)}=26.45 \mathrm{p}<0.001\right)$, and sexes $\left(\mathrm{F}_{(1,24)}=12.086 \mathrm{p}<0.01\right)$. Post hoc comparisons showed a significant decrease of CAT activity in striatum area in female and male offspring exposed to both concentrations ( $p<0.01$ for A and B concentrations) (Fig. 5).

\subsubsection{Acetylcholinesterase level}

To evaluate the activity of AChE, the levels in control and exposed offspring on the striatum were studied. Two-way ANOVA showed a significant differences between groups $\left(\mathrm{F}_{(2,24)}=21,995, \mathrm{p}<0.001\right)$. Fig. 6 shows a decrease in the AChE levels in the offspring of both sexes exposed to A and B concentrations compared to the control group $(\mathrm{p}<0.001)$.

\section{Discussion}

The present study shows that exposure to low levels of iAs/F combination during the prenatal period and during the lactation affects neither maternal weight gain during pregnancy nor the gestational length, the litter size and the pup body weight on different PNDs. However, persistent sensory-motor changes were observed in rats offspring exposed to iAs/F. Changes in the maturation of the sensory-motor reflexes, is indicative of motor activity and sensory development, which are regulated by the vestibular system and the cerebellum (Kreider and Blumberg, 2005). A delay in the development of the righting reflex was observed in female offspring whose dams had been exposed to A and $B$ concentrations. With respect to cliff aversion reflex, a development delay was observed only in female offspring exposed to B concentration. Another important found was that male offspring exposed to both concentrations exhibited a delay in cliff aversion acquisition. Another important found was that offspring exposed to A and B concentrations showed a delay in the negative geotaxis reflex maturation. A development delay may be an indicative of a myelination neuronal damage in neuronal myelination (Wu et al., 2008). Our earlier research in rats exposed during pregnancy and lactation, and exposed to low concentrations of these individual elements $(0.05$ or $0.10 \mathrm{mg} / \mathrm{L}$ of iAs) or ( 5 or $10 \mathrm{mg} / \mathrm{L} \mathrm{F}$ ) pointed out that $\mathrm{F}$ does not affect the sensory-motor development of the offspring (Bartos et al., 2015). In contrast, early iAs exposure delays righting reflex and cliff aversion in a similar manner to the co-exposure iAs/F (Gumilar et al., 2015). However, we observe greater delay in the negative geotaxis reflex maturation in iAs/F co-exposed offspring compared to the iAs exposed ones. We propose that the effect observed over these reflexes is due to the iAs expo-
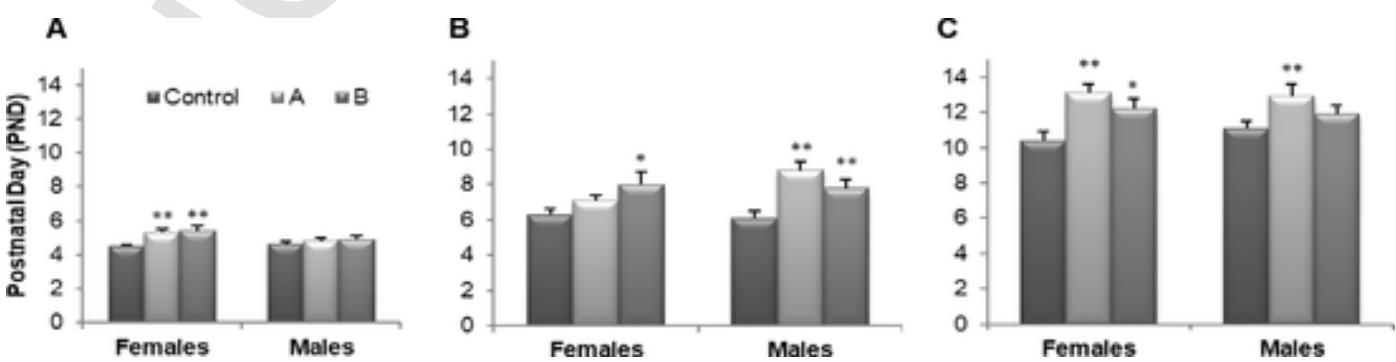

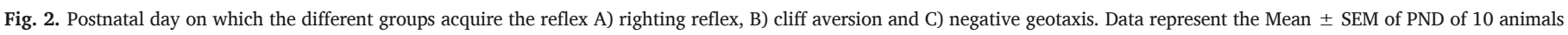
per group. ${ }^{*} \mathrm{p}<0.02,{ }^{* *} \mathrm{p}<0.01$ compared with respective control group. 
Table 2

Parameters analyzed in the Functional Observational Battery test.

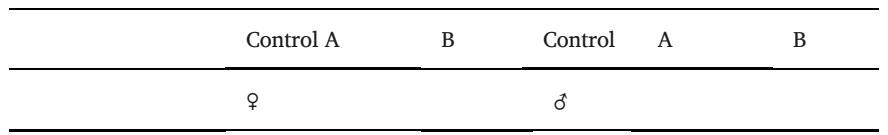

\section{Home cage}

observations:

Normal body

posture (D)

Activity (R)

Palpebral closure

(R)

Clonic

movements (D)

Tonic movements

(D)

Biting (D)

Vocalizations (B)

Hand-held

observations:

Ease of removal

from cage (R)

Ease of handling

(R)

Salivation (R)

Lacrimation (R)

Piloerection (B)

Normal fur

appearance (D)

Normal

respiration (D)

Normal

cardiovascular

signs (D)

Normal limb tone

(D)

Normal

abdominal tone

(D)

Limb grasping (B)

Open field

observations:

Normal gait (D)

Unusual

movements (D)

Stereotyped

behaviors (D)

Fecal boluses (C)

$\left(\mathrm{N}^{\circ}\right)$

Urine pools (C)

$\left(\mathrm{N}^{\circ}\right)$

Diarrhea (B)

Sensory

reflexes:

Approach

response (R)

Touch response

(R)

Click response

(R)

Tail pinch

response (R)

Palpebral reflex

(B)

Pinna reflex (B)

Eyeblink

response (B)

Motor reflexes:

\begin{tabular}{|c|c|c|c|c|c|c|}
\hline & \multicolumn{2}{|c|}{ Control A } & \multirow[t]{2}{*}{ B } & \multirow{2}{*}{$\frac{\text { Control }}{\delta}$} & \multirow[t]{2}{*}{ A } & \multirow[t]{2}{*}{$\mathrm{I}$} \\
\hline & q & & & & & \\
\hline Flexor reflex (B) & 100 & 100 & 100 & 100 & 100 & 100 \\
\hline $\begin{array}{l}\text { Extensor reflex } \\
\text { (B) }\end{array}$ & 100 & 100 & 100 & 100 & 100 & 100 \\
\hline $\begin{array}{l}\text { Forelimb hopping } \\
\text { (B) }\end{array}$ & 100 & 100 & 100 & 100 & 100 & 100 \\
\hline $\begin{array}{l}\text { Propioceptive } \\
\text { positioning (B) } \\
\text { Postural } \\
\text { reactions: }\end{array}$ & 100 & 100 & 100 & 100 & 100 & 100 \\
\hline $\begin{array}{l}\text { Forelimb } \\
\text { extension (B) }\end{array}$ & 100 & 100 & 100 & 100 & 100 & 100 \\
\hline $\begin{array}{l}\text { Hindlimb } \\
\text { extension (B) }\end{array}$ & 100 & 100 & 100 & 100 & 100 & 100 \\
\hline $\begin{array}{l}\text { Surface righting } \\
\text { reflex (R) }\end{array}$ & 1.00 & 1.00 & 1.00 & 1.00 & 1.00 & 1.00 \\
\hline $\begin{array}{l}\text { Aerial righting } \\
\text { reflex (R) }\end{array}$ & 1.00 & 1.00 & 1.00 & 1.00 & 1.00 & 1.00 \\
\hline $\begin{array}{l}\text { Landing foot } \\
\text { splay }(C)(\mathrm{cm})\end{array}$ & 5.83 & 4.28 & 5.13 & 5.60 & 5.41 & 6.91 \\
\hline
\end{tabular}

Descriptive (D) and binary (B) data expressed as percentage of incidence (Chi-square test). Ranked (R) data expressed as the mean score of the scale used (Kruskal-Wallis test).

Continuous (C) data expressed as mean value (Two-way ANOVA test).

९: female rat; $\delta$ : male rat. $\mathrm{n}=.9-10$.

${ }^{*} \mathrm{p}<0.01$ compared to control group.

sure, and that $\mathrm{F}$ would act as an enhancer. Regarding the negative geotaxis, we previously observed that male offspring exposed to $0.10 \mathrm{mg} / \mathrm{L}$ iAs delays the maturation of this reflex (Gumilar et al., 2015). Therefore, we may say that iAs/F co-exposure does not affect in the same way as in iAs exposure. We observed that the iAs/F combination affects the negative geotaxis acquisition in female offspring with both concentrations. Therefore, we may propose that $\mathrm{F}$ increases the sensitivity of female offspring. Several metals, such as arsenic, cadmium, lead or copper, can affect levels of free testosterone and estradiol ((De Craemer et al., 2017; Nagata et al., 2005). Different levels of sex hormones result in sex-specific variation in brain development. Studies have reported behavioral disorders and sex differences due to prenatal testosterone levels (Rutter et al., 2003).

An important delay in the development of eye and ear opening was detected in offspring whose mothers had been exposed to A and B concentrations, suggesting an asynchrony of maturation processes during postnatal development. Previously, in our laboratory we demonstrated that the iAs exposure during gestational and lactation at the same concentrations did not affect eyes and ears opening. In contrast, $\mathrm{F}$ exposure, at the same concentrations and exposure period, significantly affected eyes opening (Bartos et al., 2015). Therefore, we may conclude that iAs act as enhancer to F, and that a new effect appears although it is not observed when the offspring are exposed to individual elements.

FOB test showed in both female and males adult rats a low nociceptive reflex response after exposure to iAs and to $\mathrm{F}$ concentrations during gestation and lactation, thus it indicates a possible analgesic effect. No studies have been carried out up to date about the relationships between iAs/F co-exposure and intensity of tissue inflammation and related pain. Previously, we showed that exposure to $0.10 \mathrm{mg} / \mathrm{L}$ iAs during the same period significantly decreases the nociceptive reflex in adult offspring of both sexes (Gumilar et al., 2015). Therefore, we may observe that $\mathrm{F}$ acts as an enhancer to the effect produced by iAs, since we observed the nociceptive effect with both concentrations tested. The dorsal striatum is part of basal ganglia, a set of brain structures controlling voluntary movements (Albin et al., 1989). Apart from motor control, the striatum controls other functions such as so- 

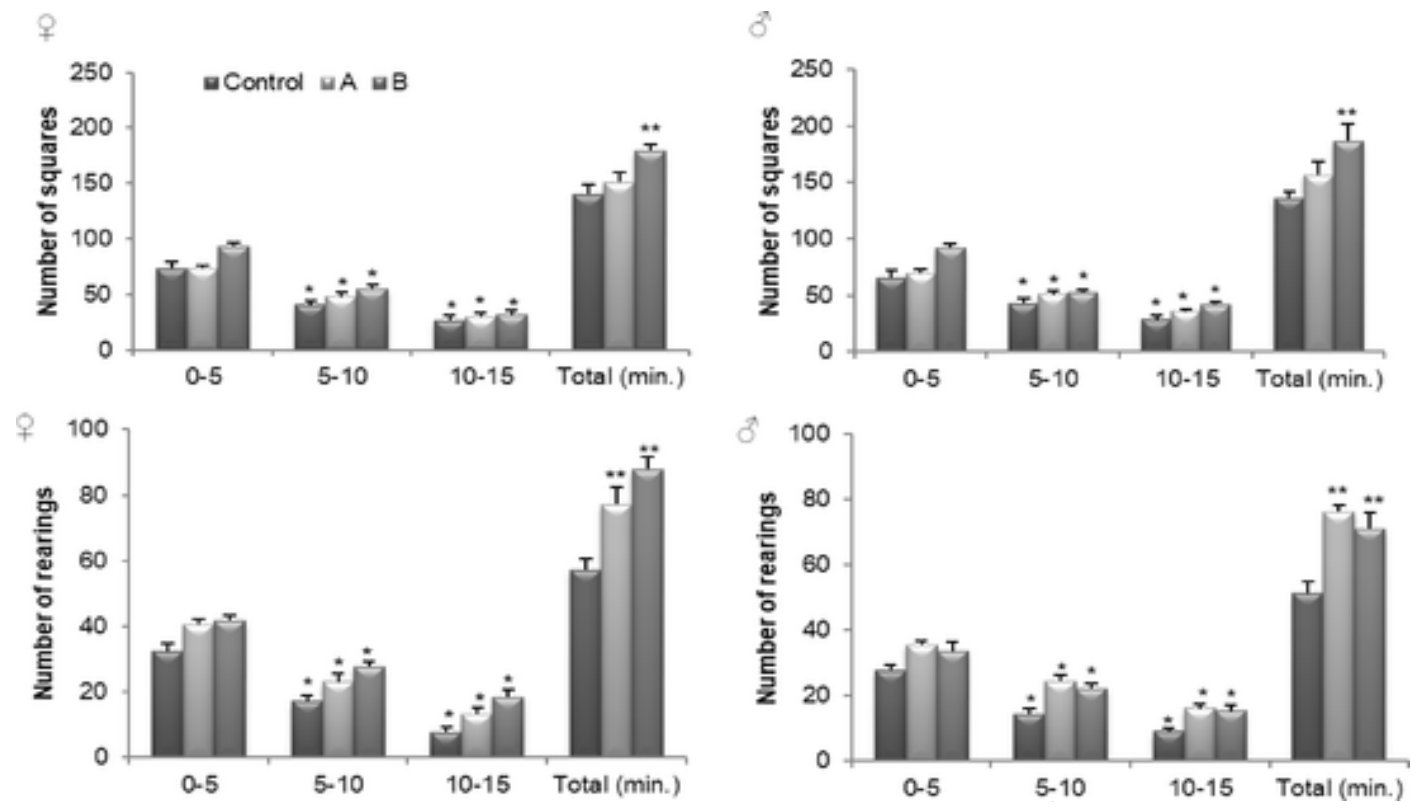

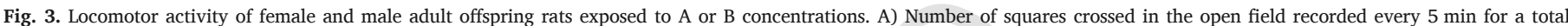

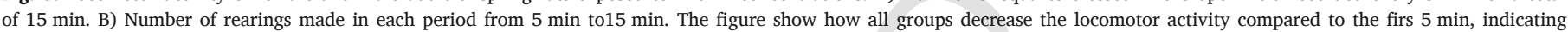

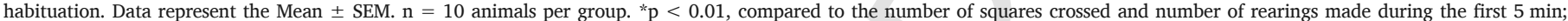
$* * \mathrm{p}<0.002$, compared to the respective control group.
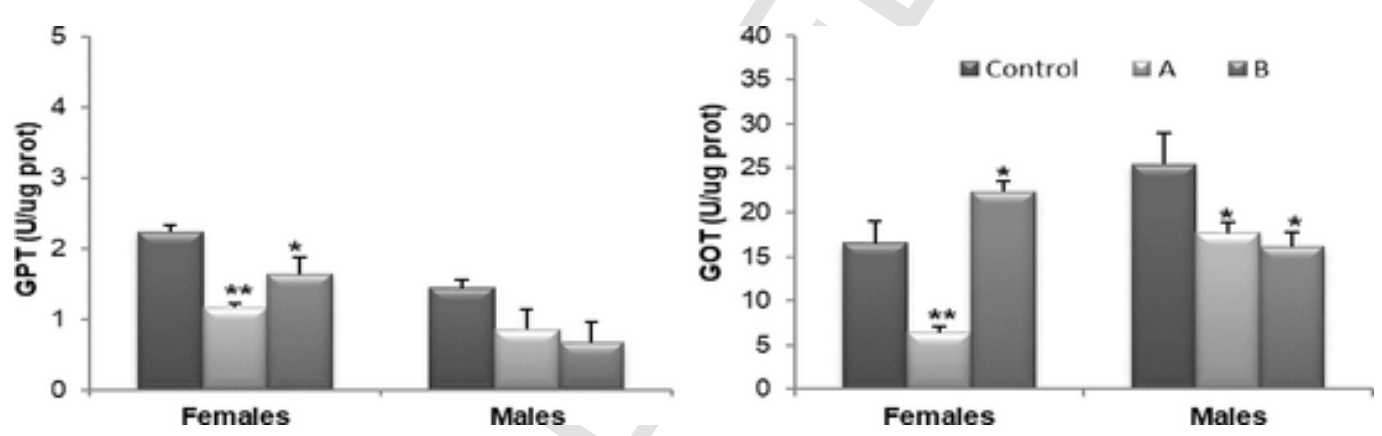

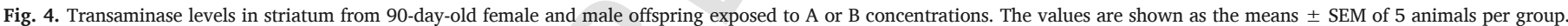
$* \mathrm{p}<0,05, * * \mathrm{p}<0.005$ compared to the control group.

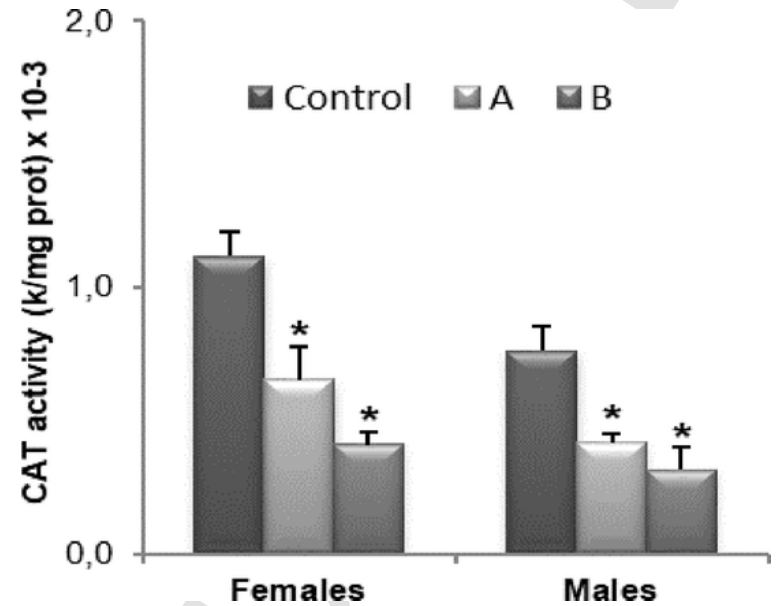

Fig. 5. Activities of CAT in the striatum of adult female and male exposed to A or B concentrations. The values are shown as the Mean \pm SEM of 5 animals per group. * $\mathrm{p}<0.01$ compared to the control group.

matosensory functions (Chudler, 1998). The dorsal striatum is activated by noxious stimulation (Coghill et al., 2003; Schneider and Lidsky, 1981) and the electrical or chemical stimulation of the stria-

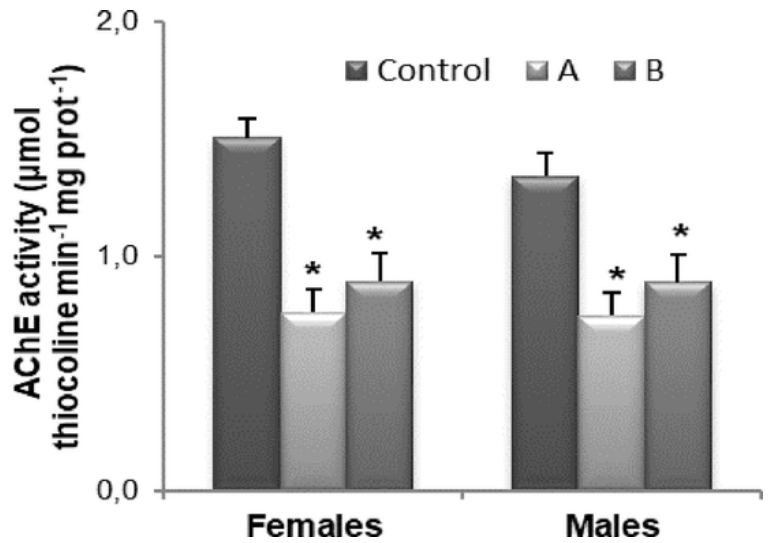

Fig. 6. Activity of AChE ( $\mu$ mol thiocoline $\min ^{-1} \mathrm{mg}$ protein ${ }^{-1}$ ) in the striatum of adult females and males exposed to A or B concentrations. Data represent the Mean \pm SEM of 5 animals per group. ${ }^{*} \mathrm{p}<0.001$ compared with respective control group.

tum inhibits pain (Barcelo et al., 2012; Gear and Levine, 2009; Nakamura et al., 2013). In fact, dorsal striatum is characterized by a large concentration of opiates and cannabinoids (Van Waes et al., 2012), neurotransmitters of the endogenous analgesic system. 
Open field test showed that co-exposure to B concentration through drinking water during gestation and lactation produce in 90-days offspring rats a significant increase in the horizontal locomotor activity. Also, the same effect was observed in female and male offspring with both concentrations in the vertical locomotor activity. Previously, we demonstrated that female offspring exposed to both iAs concentration ( 0.05 and $0.10 \mathrm{mg} / \mathrm{L} \mathrm{iAs)}$ and male exposed to the highest iAs concentration $(0.10 \mathrm{mg} / \mathrm{L}$ iAs $)$ during development presented a decrease in the locomotor activity. The number of rearings was not affected by exposure to both concentrations of iAs (Gumilar et al., 2015). In addition, we observed a decrease of the locomotor activity in adult offspring exposed to 5 and $10 \mathrm{mg} / \mathrm{L} \mathrm{F}$ during the same exposure period (Bartos et al., 2015). Therefore, we observed an antagonistic effect when mothers of the offspring evaluated were exposed to the iAs/F combination. Knowing this behavior allows us to understand that toxic substances mixtures do not always enhance or add to the effects of their individual elements. New effects may appear. Mixtures can influence expected adverse health effects because their components can individually attack the same organs or, together, overwhelm a particular mechanism the body uses to defend itself against toxic substances. Thus, mixtures can interact in the body in such a way that the combined toxicity is more serious or different than the individual toxicity (Calderon et al., 2003). Furthermore, in the open field test, our control as well as our experimental groups were found to habituate to new environments, thus confirming that the concentrations used did not affect habituation. Habituation is believed to be one of the most elementary forms of learning that involves the hippocampus, where decreasing exploration as a function of repeated exposure to the same environment is taken as an index of memory (Thiel et al., 1999).

Both the striatum (caudate nucleus and putamen) and substantia nigra are best known for their combined role in motor control. There are extensive connections between the two areas and several chemical transmitters are involved in their function. Also, the stimulation of striatum inhibits pain. For this reason, we carry out neurochemical studies in striatum brain area. We estimate the levels of catalase in the striatum of offspring exposed early to iAs/F. Previously, we demonstrate that individual iAs or F exposure during development at the same concentrations used in this study has been shown to induce a significant decrease in the antioxidant system in different brain areas in rats offspring (Bartos et al., 2019, 2018; Monaco et al., 2018). In this work, we observed in offspring exposed to both iAs/F concentrations a significant decrease of catalase in striatum. Therefore, neurobehavioral disturbances observed may be partially owing to the ROS formation in the striatum of the offspring exposed to low iAs/F concentrations during pregnancy and lactation. It is demonstrated that if antioxidant defenses are surpassed, iAs or F may also cause alterations at the transcriptional level in neurotransmission systems (Bardullas et al., 2009; Xi et al., 2010).

As regards the glutamate system, the enzymes glutamine synthetase, GOT and GPT are involved in glutamate metabolism. Glutamate is the main excitatory neurotransmitter in the CNS (Erecinska and Silver, 1990), and once released into the synaptic cleft, it must be rapidly removed (Daikhin and Yudkoff, 2000). The excess of glutamate produced excitotoxicity, that is a pathologic process by which the brain neurons are damaged and destroyed by the over activation of the glutamate receptors (Leibowitz et al., 2012).

We assessed the activities of glutamate metabolism related enzymes (GPT and GOT) in striatum. Our results showed that the activity of aspartate aminotransferase was inhibited by both iAs/F concentrations in the rat striatum of male offspring. In contrast, female offspring present a non-linear relationship between dose and response. Several researchers list nonlinear relationships in neurobehavioral studies as neurochemicals studies (Bardullas et al., 2009). As for the GPT, we observed a significant inhibition at both concentrations of iAs/F in fe- male, however, an inhibition was observed in males, but it was not significant compared to the control. Astrocytes have a crucial role removing glutamate from the synaptic cleft and metabolizing it to glutamine, a non-neuroexcitatory amino acid, which is then transferred back to neurons to be converted back to glutamate (Danbolt, 2001). Alternatively, glutamate could be oxidized to $\alpha$-ketoglutarate by the transaminases GOT and GPT (Daikhin and Yudkoff, 2000; Matthews et al., 2000). Whether to follow one or another pathway it will depend on the extracellular glutamate concentration. At low concentrations the glutamine synthetase pathway is favored, but when the external glutamate concentration is high, oxidative processes are recruited in order to prevent excitotoxic damage (McKenna et al., 1996; Torres et al., 2013).The glutamate excitotoxicity is one of the main factors for reactive oxygen species generation in brain (Bai et al., 2016; Cattani et al., 2017; Vishnoi et al., 2016). Latest clinical evidence has implicated glutamate in Attention-deficit/hyperactivity disorder (ADHD). Imaging studies of children and adults with ADHD revealed increased levels of glutamate/ glutamine in the striatum and in the prefrontal cortex (Dramsdahl et al., 2011; Moore et al., 2007, 2006). Therefore, the hyperactivity noted in open field test may be in part owing to the increase in glutamate levels in striatum area.

The striatum is one of the brain areas an exceptionally high concentration of (ACh) and its associated enzymes (Vathana et al., 2014). Cholinergic systems of the forebrain are involved in various important processes, such as attention, learning, memory and wakefulness-sleep cycle (Inglis et al., 2001). Acetylcholine is considered to participate in the conditioned choice mechanisms of motor activity (Sil'kis, 2004) and in the regulation of motor behavior (Shapovalova, 2003). Enzyme AChE ends the action of the neurotransmitter acetylcholine at the synaptic cleft by hydrolyzing it into acetic acid and choline (Thapa et al., 2017). Hyperactivity is associated with a dysregulation of ACh function in both the prefrontal cortex and and in the striatum (Viggiano, 2008). The basal ganglia have a widely-known role in motor function, and part of the mechanism underlying this role implicates a close interaction between striatal ACh and dopamine (DA) (Di Chiara et al., 1994). Moreover, these cholinergic dysfunctions may be associated with the impairment in motor coordination as it was observed in sensory-motor reflexes. Reduced AChE along the degeneration of cholinergic neurons have been reported in iAs and $\mathrm{F}$ exposed rats. It has been reported that muscarinic receptors mediate many central nervous system cholinergic function, including locomotion (Takamatsu et al., 2006). Indeed, $\mathrm{m} 1 \mathrm{mAChR}$ is abundantly expressed in the striatum (Hersch et al., 1994), and hypotheses have been proposed suggesting that $\mathrm{m} 1 \mathrm{mAChR}$ might play an important role in the extrapyramidal locomotor function regulation (Levey et al., 1991). It has been pointed out $\mathrm{m} 1 \mathrm{mAChR}$ deficiency lead to elevated striatal dopaminergic transmission and significantly increase locomotor activity (Gerber et al., 2001). Our results show that AChE activity was significantly reduced in the striatum of female and male offspring exposed to both A and B concentrations indicating an increase in ACh levels. We propose that the increased ACh levels in striatum may be down-regulating m1-AChR expression, increasing the dopaminergic transmission and consequently the locomotor activity.

In recent years, it has been shown that iAs and F could produce epigenetic modifications that produce different adverse effects on human health (Bjorklund et al., 2018; Daiwile et al., 2019). The epigenetic components play a crucial role in the regulation of gene expression, in both transcriptional and posttranscriptional levels. Changes in histone post-traslational modifications, patterns of DNA methylation, and microRNAs have been repeatedly observed after iAs and F exposure in animals and human studies. These modifications may alter the neuronal homeostasis, resulting in the modulation of key neurotransmitter pathways in iAs/F-induced neurobehavioral effects. 
In conclusion, we found iAs/F exposition during development produce a delay in sensory-motor reflexes, decrease the nociceptive reflex response, and increase the locomotor activity in adult rat offspring. All these events may partially be regulated by the neurotransmission systems present in the striatum. The increase in oxidative stress, the inhibition of transaminases enzymes and the inhibition of AChE in this brain area may partially regulate all the neurobehavioral disorders observed. It is time to raise awareness about the exposure of iAs/F, especially pregnant women and children, since these elements could produce important long-lasting disturbed in neuronal homeostasis through epigenetic mechanisms.

\section{CRediT authorship contribution statement}

Sergio Dominguez: Conceptualization, Methodology, Software, Formal analysis, Investigation, Resources. Ileana Lencinas: Methodology, Investigation, Resources. Mariana Bartos: Methodology, Software, Formal analysis. Cristina Gallegos: Methodology. Cristina Bras: Data curation, Writing - original draft, Writing - review \& editing. Nina Mónaco: Software, Validation. Alejandra Minetti: Conceptualization, Supervision. Fernanda Gumilar: Conceptualization, Data curation, Writing - original draft, Writing - review \& editing, Supervision, Funding acquisition.

\section{Declaration of Competing Interest}

The authors declare that they have no known competing financial interests or personal relationships that could have appeared to influence the work reported in this paper.

\section{Acknowledgments}

This research was supported by grants from the Secretaría General de Ciencia y Tecnología of the Universidad Nacional del Sur PGI24/B289, the National Research Council (CONICET) PIP11220130100393COand the Agencia Nacional de Promoción Científica y Tecnológica PICT2017-0312. We thank Wiener lab Argentina for the donation of transaminase kits. Nina Mónaco is a fellow of the CONICET. We are grateful to Natalia Difilippo for her assistance with English.

\section{References}

Aebi, H., 1984. Catalase in vitro. Methods Enzymol 105, 121-126.

Albin, R.L., Young, A.B., Penney, J.B., 1989. The functional anatomy of basal ganglia disorders. Trends Neurosci. 12 (10), 366-375.

Anderson, L.M., Diwan, B.A., Fear, N.T., Roman, E., 2000. Critical windows of exposure for children's health: cancer in human epidemiological studies and neoplasms in experimental animal models. Environ. Health Perspect. 108 (Suppl 3), 573-594.

Bai, X., Zhang, C., Chen, A., Liu, W., Li, J., Sun, Q., Wang, H., 2016. Protective effect of edaravone on glutamate-induced neurotoxicity in spiral ganglion neurons. Neural Plast. 2016, 4034218.

Barcelo, A.C., Filippini, B., Pazo, J.H., 2012. The striatum and pain modulation. Cell. Mol. Neurobiol. 32 (1), 1-12.

Bardullas, U., Limon-Pacheco, J.H., Giordano, M., Carrizales, L., Mendoza-Trejo, M.S., Rodriguez, V.M., 2009. Chronic low-level arsenic exposure causes gender-specific alterations in locomotor activity, dopaminergic systems, and thioredoxin expression in mice. Toxicol. Appl. Pharmacol. 239 (2), 169-177.

Bartos, M., Gumilar, F., Bras, C., Gallegos, C.E., Giannuzzi, L., Cancela, L.M., Minetti, A., 2015. Neurobehavioural effects of exposure to fluoride in the earliest stages of rat development. Physiol. Behav. 147, 205-212.

Bartos, M., Gumilar, F., Gallegos, C.E., Bras, C., Dominguez, S., Monaco, N., Esandi, M.D.C., Bouzat, C., Cancela, L.M., Minetti, A., 2018. Alterations in the memory of rat offspring exposed to low levels of fluoride during gestation and lactation: involvement of the alpha7 nicotinic receptor and oxidative stress. Reprod. Toxicol. 81, 108-114.

Bartos, M., Gumilar, F., Gallegos, C.E., Bras, C., Dominguez, S., Cancela, L.M., Minetti, A., 2019. Effects of perinatal fluoride exposure on short- and long-term memory, brain antioxidant status, and glutamate metabolism of young rat pups. Int. J. Toxicol. 38 (5), 405-414.

Basha, P.M., Madhusudhan, N., 2010. Pre and post natal exposure of fluoride induced oxidative macromolecular alterations in developing central nervous system of rat and amelioration by antioxidants. Neurochem. Res. 35 (7), 1017-1028.
Bjorklund, G., Aaseth, J., Chirumbolo, S., Urbina, M.A., Uddin, R., 2018. Effects of arsenic toxicity beyond epigenetic modifications. Environ. Geochem. Health 40 (3), 955-965.

Bradford, M.M., 1976. A rapid and sensitive method for the quantitation of microgram quantities of protein utilizing the principle of protein-dye binding. Anal. Biochem. 72, 248-254.

Britt, J.P., Benaliouad, F., McDevitt, R.A., Stuber, G.D., Wise, R.A., Bonci, A., 2012. Synaptic and behavioral profile of multiple glutamatergic inputs to the nucleus accumbens. Neuron 76 (4), 790-803.

Calderon, J., Ortiz-Perez, D., Yanez, L., Diaz-Barriga, F., 2003. Human exposure to metals. Pathways of exposure, biomarkers of effect, and host factors. Ecotoxicol. Environ. Saf. 56 (1), 93-103.

Cattani, D., Cesconetto, P.A., Tavares, M.K., Parisotto, E.B., De Oliveira, P.A., Rieg, C.E.H., Leite, M.C., Prediger, R.D.S., Wendt, N.C., Razzera, G., Filho, D.W., Zamoner, A., 2017. Developmental exposure to glyphosate-based herbicide and depressive-like behavior in adult offspring: implication of glutamate excitotoxicity and oxidative stress. Toxicology $387,67-80$.

Chudler, E.H., 1998. Response properties of neurons in the caudate-putamen and globus pallidus to noxious and non-noxious thermal stimulation in anesthetized rats. Brain Res. 812 (1-2), 283-288.

Coghill, R.C., McHaffie, J.G., Yen, Y.F., 2003. Neural correlates of interindividual differences in the subjective experience of pain. Proc. Natl. Acad. Sci. U. S. A. 100 (14), 8538-8542.

Daikhin, Y., Yudkoff, M., 2000. Compartmentation of brain glutamate metabolism in neurons and glia. J. Nutr. 130 (4S Suppl), 1026S-1031S.

Daiwile, A.P., Tarale, P., Sivanesan, S., Naoghare, P.K., Bafana, A., Parmar, D., Kannan, K., 2019. Role of fluoride induced epigenetic alterations in the development of skeletal fluorosis. Ecotoxicol. Environ. Saf. 169, 410-417.

Danbolt, N.C., 2001. Glutamate uptake. Prog. Neurobiol. 65 (1), 1-105.

De Craemer, S., Croes, K., van Larebeke, N., De Henauw, S., Schoeters, G., Govarts, E., Loots, I., Nawrot, T., Nelen, V., Den Hond, E., Bruckers, L., Gao, Y., Baeyens, W., 2017. Metals, hormones and sexual maturation in Flemish adolescents in three cross-sectional studies (2002-2015). Environ. Int. 102, 190-199.

Di Chiara, G., Morelli, M., Consolo, S., 1994. Modulatory functions of neurotransmitters in the striatum: ACh/dopamine/NMDA interactions. Trends Neurosci. 17 (6), 228-233.

Dramsdahl, M., Ersland, L., Plessen, K.J., Haavik, J., Hugdahl, K., Specht, K., 2011. Adults with attention-deficit/hyperactivity disorder - a brain magnetic resonance spectroscopy study. Front. Psychiatry 2, 65.

Ellman, G.L., Courtney, K.D., Andres, V., Jr., Feather-Stone, R.M., 1961. A new and rapid colorimetric determination of acetylcholinesterase activity. Biochem. Pharmacol. 7, 88-95.

Erecinska, M., Silver, I.A., 1990. Metabolism and role of glutamate in mammalian brain. Prog. Neurobiol. 35 (4), 245-296.

Fangstrom, B., Moore, S., Nermell, B., Kuenstl, L., Goessler, W., Grander, M., Kabir, I., Palm, B., Arifeen, S.E., Vahter, M., 2008. Breast-feeding protects against arsenic exposure in Bangladeshi infants. Environ. Health Perspect. 116 (7), 963-969.

Flora, S.J., Mittal, M., Pachauri, V., Dwivedi, N., 2012. A possible mechanism for combined arsenic and fluoride induced cellular and DNA damage in mice. Metallomics 4 (1), 78-90.

Gear, R.W., Levine, J.D., 2009. Rostral ventral medulla cholinergic mechanism in pain-induced analgesia. Neurosci. Lett. 464 (3), 170-172.

Gerber, D.J., Sotnikova, T.D., Gainetdinov, R.R., Huang, S.Y., Caron, M.G., Tonegawa, S., 2001. Hyperactivity, elevated dopaminergic transmission, and response to amphetamine in M1 muscarinic acetylcholine receptor-deficient mice. Proc. Natl. Acad. Sci. U.S.A. 98 (26), 15312-15317.

Gonzalez-Horta, C., Ballinas-Casarrubias, L., Sanchez-Ramirez, B., Ishida, M.C., Barrera-Hernandez, A., Gutierrez-Torres, D., Zacarias, O.L., Saunders, R.J., Drobna, Z., Mendez, M.A., Garcia-Vargas, G., Loomis, D., Styblo, M., Del Razo, L.M., 2015. A concurrent exposure to arsenic and fluoride from drinking water in Chihuahua, Mexico. Int J Environ Res Public Health 12 (5), 4587-4601.

Grandjean, P., Weihe, P., Debes, F., Choi, A.L., Budtz-Jorgensen, E., 2014. Neurotoxicity from prenatal and postnatal exposure to methylmercury. Neurotoxicol. Teratol. 43, $39-44$.

Gumilar, F., Lencinas, I., Bras, C., Giannuzzi, L., Minetti, A., 2015. Locomotor activity and sensory-motor developmental alterations in rat offspring exposed to arsenic prenatally and via lactation. Neurotoxicol. Teratol. 49, 1-9.

Hersch, S.M., Gutekunst, C.A., Rees, H.D., Heilman, C.J., Levey, A.I., 1994. Distribution of $\mathrm{m} 1-\mathrm{m} 4$ muscarinic receptor proteins in the rat striatum: light and electron microscopic immunocytochemistry using subtype-specific antibodies. J. Neurosci. Off. J. Soc Neurosci. 14 (5 Pt 2), 3351-3363.

Hubler, N., Gottschling, B., Jacobs, M., von Landenberg, F., Hewicker-Trautwein, M., 2005. Functional observational battery and motor activity in rats after single administration of two NHE 1 inhibitors. Toxicol. Appl. Pharmacol. 208 (3), 266-276.

Inglis, W.L., Olmstead, M.C., Robbins, T.W., 2001. Selective deficits in attentional performance on the 5-choice serial reaction time task following pedunculopontine tegmental nucleus lesions. Behav. Brain Res. 123 (2), 117-131.

Khan, S.A., Singh, R.K., Navit, S., Chadha, D., Johri, N., Navit, P., Sharma, A., Bahuguna, R., 2015. Relationship between dental fluorosis and intelligence quotient of school going children in and around Lucknow district: a cross-sectional study. J. Clin. Diagn. Res. 9 (11), ZC10-15.

Kreider, J.C., Blumberg, M.S., 2005. Geotaxis and beyond: commentary on Motz and Alberts (2005). Neurotoxicol. Teratol. 27 (4), 535-537 author reply 543-534.

Leibowitz, A., Boyko, M., Shapira, Y., Zlotnik, A., 2012. Blood glutamate scavenging: insight into neuroprotection. Int. J. Mol. Sci. 13 (8), 10041-10066.

Levey, A.I., Kitt, C.A., Simonds, W.F., Price, D.L., Brann, M.R., 1991. Identification and localization of muscarinic acetylcholine receptor proteins in brain with subtype-specific antibodies. J. Neurosci. Off. J. Soc. Neurosci. 11 (10), 3218-3226. 
Liu, H., Sun, J.C., Zhao, Z.T., Zhang, J.M., Xu, H., Li, G.S., 2011. Fluoride-induced oxidative stress in three-dimensional culture of OS732 cells and rats. Biol. Trace Elem. Res. 143 (1), 446-456.

Luo, J.H., Qiu, Z.Q., Shu, W.Q., Zhang, Y.Y., Zhang, L., Chen, J.A., 2009. Effects of arsenic exposure from drinking water on spatial memory, ultra-structures and NMDAR gene expression of hippocampus in rats. Toxicol. Lett. 184 (2), 121-125.

Maimanee, T.A., Brain, P.F., Zari, T.A., 2003. Dietary fats influence' open-field' behaviour of male and female laboratory mice. Lab Anim 37 (3), 222-232.

Matthews, C.C., Zielke, H.R., Wollack, J.B., Fishman, P.S., 2000. Enzymatic degradation protects neurons from glutamate excitotoxicity. J. Neurochem. 75 (3), 1045-1052.

McDaniel, K.L., Moser, V.C., 1993. Utility of a neurobehavioral screening battery for differentiating the effects of two pyrethroids, permethrin and cypermethrin. Neurotoxicol. Teratol. 15 (2), 71-83.

McKenna, M.C., Sonnewald, U., Huang, X., Stevenson, J., Zielke, H.R., 1996. Exogenous glutamate concentration regulates the metabolic fate of glutamate in astrocytes. J. Neurochem. 66 (1), 386-393.

Molina, J.C., Hoffmann, H., Spear, L.P., Spear, N.E., 1987. Sensorimotor maturation and alcohol responsiveness in rats prenatally exposed to alcohol during gestational day 8 . Neurotoxicol. Teratol. 9 (2), 121-128.

Monaco, N.M., Bartos, M., Dominguez, S., Gallegos, C., Bras, C., Esandi, M.D.C., Bouzat, C., Giannuzzi, L., Minetti, A., Gumilar, F., 2018. Low arsenic concentrations impair memory in rat offpring exposed during pregnancy and lactation: Role of alpha7 nicotinic receptor, glutamate and oxidative stress. Neurotoxicology 67, 37-45.

Moore, C.M., Biederman, J., Wozniak, J., Mick, E., Aleardi, M., Wardrop, M., Dougherty, M., Harpold, T., Hammerness, P., Randall, E., Renshaw, P.F., 2006. Differences in brain chemistry in children and adolescents with attention deficit hyperactivity disorder with and without comorbid bipolar disorder: a proton magnetic resonance spectroscopy study. Am. J. Psychiatry 163 (2), 316-318.

Moore, C.M., Biederman, J., Wozniak, J., Mick, E., Aleardi, M., Wardrop, M., Dougherty, M., Harpold, T., Hammerness, P., Randall, E., Lyoo, I.K., Renshaw, P.F., 2007. Mania, glutamate/glutamine and risperidone in pediatric bipolar disorder: a proton magnetic resonance spectroscopy study of the anterior cingulate cortex. J. Affect. Disord. 99 (1-3), 19-25.

Nagata, C., Nagao, Y., Shibuya, C., Kashiki, Y., Shimizu, H., 2005. Urinary cadmium and serum levels of estrogens and androgens in postmenopausal Japanese women. Cancer Epidemiol. Biomarkers Prev. 14 (3), 705-708.

Nakamura, Y., Izumi, H., Shimizu, T., Hisaoka-Nakashima, K., Morioka, N., Nakata, Y., 2013. Volume transmission of substance $P$ in striatum induced by intraplantar formalin injection attenuates nociceptive responses via activation of the neurokinin 1 receptor. J. Pharmacol. Sci. 121 (4), 257-271.

Paxinos, G., Watson, C., 2007. The Rat Brain in Stereotaxic Coordinates. Academic Press/ Elsevier.

Rodriguez, V.M., Carrizales, L., Mendoza, M.S., Fajardo, O.R., Giordano, M., 2002. Effects of sodium arsenite exposure on development and behavior in the rat. Neurotoxicol. Teratol. 24 (6), 743-750.

Rodriguez, V.M., Limon-Pacheco, J.H., Carrizales, L., Mendoza-Trejo, M.S., Giordano, M., 2010. Chronic exposure to low levels of inorganic arsenic causes alterations in locomotor activity and in the expression of dopaminergic and antioxidant systems in the albino rat. Neurotoxicol. Teratol. 32 (6), 640-647.
Rutter, M., Caspi, A., Moffitt, T.E., 2003. Using sex differences in psychopathology to study causal mechanisms: unifying issues and research strategies. J. Child Psychol. Psychiatry 44 (8), 1092-1115.

Schneider, J.S., Lidsky, T.I., 1981. Processing of somatosensory information in striatum of behaving cats. J. Neurophysiol. 45 (5), 841-851.

Sener, Y., Tosun, G., Kahvecioglu, F., Gokalp, A., Koc, H., 2007. Fluoride levels of human plasma and breast milk. Eur. J. Dent. 1 (1), 21-24.

Shapovalova, K.B., 2003. Advances in Functional Neurochemistry. pp. 231-244.

Sil'kis, I.G., 2004. [A possible mechanism of participation of dopaminergic cells and striatal cholinergic interneurons in the conditioned selection of motor activity]. Zh. Vyssh. Nerv. Deiat. Im. I P Pavlova 54 (6), 734-749.

Takamatsu, Y., Yamanishi, Y., Hagino, Y., Yamamoto, H., Ikeda, K., 2006. Differential effects of donepezil on methamphetamine and cocaine dependencies. Ann. N. Y. Acad. Sci. 1074, 418-426.

Thapa, S., Lv, M., Xu, H., 2017. Acetylcholinesterase: a primary target for drugs and insecticides. Mini Rev. Med. Chem. 17 (17), 1665-1676.

Thiel, C.M., Muller, C.P., Huston, J.P., Schwarting, R.K., 1999. High versus low reactivity to a novel environment: behavioural, pharmacological and neurochemical assessments. Neuroscience 93 (1), 243-251.

Torres, F.V., Hansen, F., Locks-Coelho, L.D., 2013. Increase of extracellular glutamate concentration increases its oxidation and diminishes glucose oxidation in isolated mouse hippocampus: reversible by TFB-TBOA. J. Neurosci. Res. 91 (8), 1059-1065.

Van Waes, V., Beverley, J.A., Siman, H., Tseng, K.Y., Steiner, H., 2012. CB1 cannabinoid receptor expression in the striatum: association with corticostriatal circuits and developmental regulation. Front. Pharmacol. 3, 21.

Vathana, T., Nijhuis, T.H., Friedrich, P.F., Bishop, A.T., Shin, A.Y., 2014. An experimental study to determine and correlate choline acetyltransferase assay with functional muscle testing after nerve injury. J. Neurosurg. 120 (5), 1125-1130.

Viggiano, D., 2008. The hyperactive syndrome: metanalysis of genetic alterations, pharmacological treatments and brain lesions which increase locomotor activity. Behav. Brain Res. 194 (1), 1-14.

Vishnoi, S., Raisuddin, S., Parvez, S., 2016. Glutamate excitotoxicity and oxidative stress in epilepsy: modulatory role of melatonin. J. Environ. Pathol. Toxicol. Oncol. 35 (4), 365-374.

Wasserman, G.A., Liu, X., Parvez, F., Ahsan, H., Factor-Litvak, P., van Geen, A., Slavkovich, V., LoIacono, N.J., Cheng, Z., Hussain, I., Momotaj, H., Graziano, J.H., 2004. Water arsenic exposure and children's intellectual function in Araihazar, Bangladesh. Environ. Health Perspect. 112 (13), 1329-1333.

Wu, L.L., Zhang, L., Shao, J., Qin, Y.F., Yang, R.W., Zhao, Z.Y., 2008. Effect of perinatal iron deficiency on myelination and associated behaviors in rat pups. Behav. Brain Res. 188 (2), 263-270.

Xi, S., Sun, W., Wang, F., Jin, Y., Sun, G., 2009. Transplacental and early life exposure to inorganic arsenic affected development and behavior in offspring rats. Arch. Toxicol. 83 (6), 549-556.

Xi, S., Jin, Y., Lv, X., Sun, G., 2010. Distribution and speciation of arsenic by transplacental and early life exposure to inorganic arsenic in offspring rats. Biol. Trace Elem. Res. 134 (1), 84-97. 